\title{
Anti-Neuropilin-1 Monoclonal Antibody MNRP1685A
}

National Cancer Institute

\section{Source}

National Cancer Institute. Anti-Neuropilin-1 Monoclonal Antibody MNRP1685A. NCI

Thesaurus. Code C91728.

A human IgG1 monoclonal antibody directed against neuropilin-1 (NRP1), with potential antiangiogenic and antineoplastic activities. Upon intravenous administration, MNRP1685A specifically targets and binds to NRP1; the antibody-NRP1 complex prevents the subsequent coupling of NRP1 to VEGFR2, thereby potentially inhibiting VEGF-mediated signaling and potentially preventing ang iogenesis. In combination with other anti-VEGF therapies, MNRP1685A may enhance their anti-angiogenic effect. NRP1 is a membrane-bound co-receptor normally expressed by endothelial cells and overexpressed by certain tumor cells, and plays a role in angiogenesis, cell survival, migration, and invasion. 